pequena e média empresta

1. Introdução;

2. Objetivos;

3. Justificativa;

4. Critérios para caracterizar empresas;

5. Revisão da literatura de marketing de micro/pequena empresa;

6. Conchusäo

\section{As micro e pequenas empresas: uma revisáo da literatura de marketing e os critérios para caracterizá-las}

\author{
Ivan Dutra \\ Da FEA /USP \\ José Augusto Guagliardi \\ Da FEA/USP
}

\section{INTROQDUÇÃO}

As micro e pequenas empresas continuam representando parcela significativa da geração e manutençăo de emprego no Brasil. Ocorre que as empresas desses portes são as mais vulneráveis em épocas de crise econômica, como a que o mundo e principalmente o Brasil está enfrentando. Prova disso são os pedidos de concordata, falência títulos protestados que chegam mensalmente aos cartórios. Prevê-se que durante o primeiro semestre de 1983 os pedidos de falência requeridos por essas empresas alcance aproximadamente o total de 3.500 e, dessas, quase 500 fecharø̃o suas portas.

Essa vulnerabilidade tem origem em dois fatores: um conjuntural, relacionado com a situação económica que tem afetado empresas, governo e indivíduos; outro, interno, que se relaciona com 0 aspecto gerencial de empresas deste porte.

\section{OBJETIVOS}

1. Justificar a importancia de se estudar e compreender a micro e a pequena empresa no Brasil.
2. Revisar a literatura deste porte de empresa, explorando principalmente seus aspectos gerenciais e de mercado.

3. Identificar os diferentes critérios para caracterizar as micro e pequenas empresas.

4. Servir de literatura básica para testar hipóteses de aspectos gerenciais e mercado para esses portes de empresas.

\section{JUSTIFICATIVA}

A base fundamental do sistema capitalista a economia de mercado, que sem dúvida se alicerça na iniciativa privada. Esta por sua vez é a mola mestra do desenvolvimento dos países que adotam aquele sistema econômico.

Dentro do âmbito da empresa privada, os govemos e os estudiosos têm avaliado os diferentes portes de empresas, tradicionalmente segmentados em grande, médio e pequeno.

E inegável a contribuiçåo que as grandes corporações dão para as economias do mundo ocidental; entretanto, tem sido cada vez mais reconhecido o papel relevante que as pequenas e médias empresas também têm representado, não só em termos sociais, como empregadoras da maior parte da população ativa, mas também pela sua participação no produto nacional.

E justamente para preservar a estabilidade e a dinâmica da economia de mercado que a existência do menor dos três segmentos empresariais, ou seja, a pequena empresa, tem sido considerada fundamental em muitos dos países ocidentais. A concorréncia, mesmo que imperfeita, não pode ser eliminada e a crescente participação no mercado das grandes corporaçðes tem criado vários problemas.

Mesmo nos EUA os analistas têm condenado a concentraçáo dos meios de produção, argumentando que o big business, usando freqüientemente do poder monopolístico, enfraquece a sustentaçro política do sistema de livre empresa e ño é significativamente mais empreendedor que as médias empresas (Rattner et alii, 1979).

A existência indubitável das grandes organizaçotes nas sociedades mais industrializadas náo obriga necessariamente o desaparecimento das pequenas empresas; ao contrário, uma estrutura industrial poderá ser mais produtiva num país se as pequenas indústrias preencherem, pelas suas características próprias, as lacunas deixadas pelas grandes.

Nos países europeus mais adiantados, as empresas de menor porte têm papel relevante. Na Alemanha Ocidental, por exemplo, $96 \%$ das empresas do setor industrial pertencem à faixa de pequenas e médias, conforme afirma Wipplinger (1980), acrescentando que "só pode se desenvolver o país que tenha o setor de pequena e média empresas (PME) néo mais em puras condiçoes de sobrevivência, mas sim como um setor dinámico e pujante de sua economia".

Situaçæo semelhante a a existente nos EUA e no Reino Unido, nos quais, segundo dados levantados por Barros \& Modenesi (1973), as pequenas indústrias participam com cerca de $90 \%$ dos estabelecimentos, empregando cerca de $27 \%$ da forca de trabalho e contribuindo 
para o valor da transformação industrial som $23 \%$. No Japão a participação é maior, com $98 \%$ de pequenas empresas, empregando $56 \%$ da máo-de-obra do país e participando com $34 \%$ do valor de transformaçáo.

No Brasil, tem sido uma preocupaçá do governo federal fortalecer as empresas privadas nacionais e em es. pecial as de pequeno porte. Estas devem ser fortalecidas porque atuam em todo o território nacional, o que permite uma desconcentraçáo de atividade econômica e maior geração e distribuição regional de empregos.

Até fins da década de 50, a microempresa estava incorporada no segmento destinado d̀ pequena empresa. 0 próprio IBGE, ao classificar os segmentos industriais, o fazia considerando apenas três: a pequena, a média e a grande empresa.

Isto se deu porque normalmente o menor segmento empresarial considerado nas análises e nos programas governamentais era o da pequena empresa.

Em 1970, mais de 90\% dos estabelecimentos industriais estavam classificados na faixa das pequenas empresas (Anuário brasileiro de estatística, 1970), sendo consideradas dentro deste segmento as indústrias que tinham até 100 empregados.

A tabela 1 mostra que a situaçáo mudou pouco 10 anos depois. Segundo o mesmo Anuärio, porém em 1980 , a faixa de até 99 pessoas ocupadas perfaz $92 \%$ das empresas, agora dividida nos dois menores segmentos: micro e pequena empresas.

Tabela 1

Número de estabelecimentos pelo porte das indústrias *

\begin{tabular}{lccr}
\hline $\begin{array}{l}\text { Segmentos } \\
\text { industriais }\end{array}$ & $\begin{array}{c}\text { Pessoal } \\
\text { ocupado }\end{array}$ & $\begin{array}{l}\text { Número de } \\
\text { estabelecimentos }\end{array}$ & $\%$ \\
\hline Sem declarar & - & 1.295 & 1,3 \\
Micro & Até 19 pessoas & 73.898 & 68,9 \\
Pequena & De 20 a 99 & 24.645 & 23,0 \\
Média & 100 a 499 & 6.490 & 6,1 \\
Grande & 500 ou mais & 783 & 0,7 \\
Total & & 107.111 & 100,0 \\
\hline
\end{tabular}

Fonte: IBGE. Anudrio brasileiro de estattstica. 1980.

"Não está incluída a indústria extrativa.

A grande importância da micro e pequena indústria no Brasil está no número de empregos que oferecem para - mercado de trabalho. A tabela 2 evidencia que estes dois segmentos industriais são importantíssimos como fonte geradora de empregos, um dos maiores problemas sócio-conômicos que preocupam o governo e a sociedade brasileira nos últimos anos. Além disto, eles têm uma

Tabela 2

Número de pessoal ocupado e valor da produção por segmento industrial

\begin{tabular}{lrrcr}
\hline $\begin{array}{l}\text { Segmentos } \\
\text { industriais }\end{array}$ & $\begin{array}{c}\text { Pessoal } \\
\text { ocupado }\end{array}$ & $\%$ & $\begin{array}{l}\text { Valor transformado } \\
\text { (em Cr } \$ \text { milhzes) }\end{array}$ & $\%$ \\
\hline Micro & 589.001 & 16,3 & 33.344 & 10,9 \\
Pequena & 1.034 .061 & 28,5 & 76.053 & 24,9 \\
Média & 1.303 .466 & 35,9 & 122.465 & 40,2 \\
Grande & 701.050 & 19,3 & 73.196 & 24,0 \\
Total & 3.627 .578 & 100,0 & 305.058 & 100,0 \\
\hline
\end{tabular}

Fonte: IBGE. Anudrio brasiletro de estattstica. 1980. importância significativa no valor de transformação industrial.

Através da comparaçáo entre as tabelas 2 e 3 dá para se ter uma idéia da evoluçáo em 10 anos, mostrando que a pequena empresa participava em 1970 com $29,59 \%$ da produção industrial, enquanto em 1980 essa participação aumentou para $35,8 \%$. Fica ainda evidenciado que a pequena empresa participava em 1970 com 34,92\% da oferta de empregos, enquanto em 1980 o percentual aumentou para $44,8 \%$.

Tabela 3

Pessoal ocupado e valor da produção por segmento industrial -1970

\begin{tabular}{lcccc}
\hline $\begin{array}{l}\text { Faixa de } \\
\text { indústrias }\end{array}$ & $\begin{array}{c}\text { Pessoal } \\
\text { ocupado }\end{array}$ & \multicolumn{1}{c}{$\%$} & $\begin{array}{c}\text { Valor de produção } \\
\text { (em Cr\$ milhōes) }\end{array}$ & \multicolumn{1}{c}{$\%$} \\
\hline Pequena & $1.11 \% .130$ & 34,92 & 94.144 & 29,59 \\
Média & 1.125 .494 & 35,18 & 144.373 & 35.95 \\
Grande & 956.667 & 29,90 & 109.628 & 34,46 \\
Total & 3.199 .291 & 100,00 & 348.145 & 100,00 \\
\hline
\end{tabular}

Fonte: IBGE. Anudrio estattstico. 1970.

\section{CRITERIOS PARA CARACTERIZAR EMPRESAS}

É comum se usarem indistintamente os termos "pequenas empresas" ou "microempresas". Entretanto, cada um tem o seu significado próprio e, assim, cumpre-nos tentar definir o sentido de tais expressores.

Existem vários critérios para caracterizar as pequenas, médias e grandes empresas. Podem-se dividir esses critérios em dois grandes grupos: quantitativos e qualitativos.

Tais critérios obedecem a alguns parâmetros que servem para caracterizar a empresa segundo a sua dimensão e desenvolvimento.

\subsection{Pequena empresa}

No que se refere as pequenas empresas, podemos verificar os seguintes critérios:

\subsubsection{Critérios quantitativos}

- Os parâmetros mais importantes sáo:

1. Número de empregados. E um critério bastante usado, se bem que combinado com outras formas de mensuraçấ de uma empresa. E o parâmetro utilizadơ pela Fibge (1970) e por Stanley \& Morse (1965).

Carmelo \& Schoeps (1970) consideram pequena empresa aquela com menos de 100 empregados, quando comentam a importância dela na manufatura do Japăo.

Foi também critério utilizado pela Cepal (Comisstó Económica para a América Latina), ,que adotou no estudo feito o parâmetro de cinco a 49 empregados para caracterizar a pequena indústria. Tal critério foi escolhido pelo Paraguai, Uruguai e América Central, variando o número de pessoas da pequena empresa de cinco a 14 até cinco a 49 empregados.

2. Faturamento ou receita anual. Esta forma de caracterizaça do tamanho da empresa foi a utilizada pelo im- 
posto de renda (1966) em seus arts. 19 e 20 , quando fala em receita bruta, náo obstante usar, além deste parámetro, o capital nos arts. 194 e 195 do mesmo Regulamen. to.

O Banco Central, através de suas Resoluçóes n $\mathrm{O}^{\mathrm{S}}$ 130/ $70,172 / 71,208 / 72,214 / 73,282 / 74$ e $388 / 76$, tem adotado o critério citado para regulamentar o financiamento ds pequenas e médias empresas. Inicialmente, o Barico Central utilizou valores em cruzeiros para os limites de vendas anuais, como no caso da Resoluçáo n९ 130/70, que considerou PME as que tinham vendas anuais de até Cr\$ 9 milhoes novos. Posteriormente, talvez em vista das desvalorizaçøes do cruzeiro, passou a usar o salário mínimo, como aconteceu com a Resoluçấo n? 295, que estipulou que as PME seriam aquelas que não ultrapassem 70 mil vezes o maior salário mínimo vigente do país. Mais tarde passou a usar o Maior Valor de Referência (MVR), como é o caso da Resolução no 388/76, unidade de medida também adotada pelo Cebrae e Banco do Bra. sil (1979).

Ultimamente, foi o parâmetro de "vendas anuais" o utilizado pelo Decreto-lei no 1.780 , de 1980 , que isentou do imposto sobre a renda as microempresas com faturamento igual ou inferior a 3 mil ORTN.

3. Patrimônio líquido. $O$ Banco Central, ao regulamentar a aplicaçáo dos Fundos 157 para as sociedades por açóes de pequeno e médio porte, considerou como tais um válor máximo (140 mil MSM de capital e reservas).

4. Capital Social. Além dos outros critérios já citados, o Banco Central (Resoluçáo nP 184, de 20 de maio de 1971) utilizou também o parâmetro do capital social, ao regulamentar as aplicaçóes do depósito compulsório em pequenas e médias empresas.

Também Equador, México e Peru utilizam o critério do capital social para caracterizar a pequena indústria, conforme acentuou Fracarolli (1975).

5. Ativo imobilizado. É o critério utilizado pelo BNDE e Sudene (Portaria no 001, de 22 de outubro de 1975) para financiamento ds pequenas empresas.

O Fipeme, criado pelo BNDE (Resoluçáo n9 166/65) considera os seus beneficiários as empresas pequenas e médias cujo ativo imobilizado vai até um determinado limite estabelecido periodicamente.

6. Valor do passivo. É o critério usado para a definiçáo legal de "pequenas falências" (Lei federal no 4.983/66).

\subsubsection{Critérios qualitativos}

Entendem-se como qualitativos os aspectos que tentam caracterizar pequena, média e grande empresas sem utilizar valores numéricos, como os critérios de que:

- usam trabalho próprio ou de familiares;

- não possuem administraçáo especializada;

- náo pertencem a grupos financeiros;

- não têm produção em escala;

- apresentam condiçoes peculiares de atividade revelado-

ras de exigüidade de negócio;

- sáo organizaç6́es rudimentares;
- apresentam menor complexidade do equipamento produtivo causando baixa rela çăo investimento/máo-de-obra; - são receptoras da máo-de-obra liberada do setor rural; - sấo campo de treinamento de máo-de-obra especializada e formação do empresário.

Por uma análise rápida dos aspectos mencionados, podemos concluir, pelo bom senso, que nenhum deles pode sozinho caracterizar o que seja uma pequena ou uma grande empresa. Destarte, eles costumam sempre aparecer complementando ou reforçando parâmetros já existentes.

\subsubsection{Critérios mistos}

O grupo de trabalho criado pelo Decreto no 77.941, de 30 de junho de 1976, com o objetivo de propor um programa especial de apoio à pequena e média empresa, estabeleceu um critério quantitativo para a pequena indústria de produção anual inferior a 3 mil salários mínimos, além de um qualitativo que assim se configura:

- baixa relação investimento/mão-de-obra empregada, decorrente de menor complexidade do equipamento produtivo, o que as capacita a gerar emprego a menor custo social e privado;

- menor dependência das fontes externas de tecnologia;

- papel complementar ds atividades industriais mais complexas;

- extensa rede de produçáo e distribuiçáo de bens e serviços, o que contribui decisivamente para a desconcentraçâo industrial;

- suporte à política de apoio ds cidades de porte médio, viabilizando a utilizaçáo de recursos locais disponiveis e retendo a máo-de-obra liberada do setor rural, antes de seu deslocamento para os centros urbanos congestionados;

Quadro 1

Critérios para classificar pequenas empresas

\begin{tabular}{|c|c|c|}
\hline Quantitativos & Qualitativos & Mistos \\
\hline $\begin{array}{l}\text { Número de empre- } \\
\text { gados } \\
\text { Faturamento/re- } \\
\text { ceita anual } \\
\text { Patrimómio líqui- } \\
\text { quido } \\
\text { Capital social } \\
\text { Ativo imobilizado } \\
\text { Vabor do passivo' }\end{array}$ & 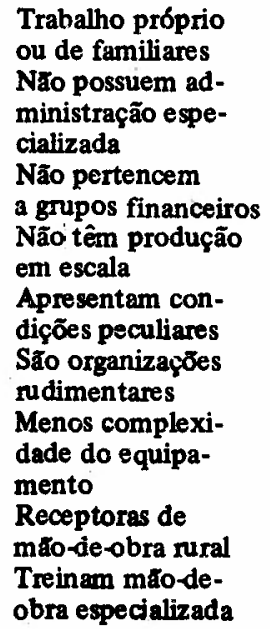 & $\begin{array}{l}\text { Baixa relação investi- } \\
\text { mento/mão-de-obra } \\
\text { empregada } \\
\text { Menor dependéncia } \\
\text { a fontes externas tec- } \\
\text { nológicas } \\
\text { Completam ativida- } \\
\text { des de indústrias } \\
\text { complexas } \\
\text { Extensa rede de pro- } \\
\text { dução/distribuição } \\
\text { de bens/serviços } \\
\text { Suporte à política } \\
\text { de apoio a cidades } \\
\text { de porte médio } \\
\text { Prepara executivos e } \\
\text { futuros empresários }\end{array}$ \\
\hline
\end{tabular}


- campo de treinamento de máo-de-obra especializada e de formação de empresários.

O Decreto-lei no 486, de 3 março de 1969, define o pequeno comerciante com os seguintes critérios:

- natureza artesanal de atividade;

- predominância do trabalho próprio e de familiares;

- capital empregado;

- renda bruta anual.

No quadro 1, é apresentado um sumário dos critérios para classificar pequenas empresas.

\subsection{Microempresa}

\subsubsection{Critérios existentes}

Observou-se que não é pacífico o entendimento sobre a classificacáo das empresas segundo o seu porte. Além disso, a tentativa de distinçáo entre micro e pequena empresa é recente, porque aquela estava sempre enquadrada junto a esta. Por isso, ainda náo existem muitos critérios para definir a microempresa. Contudo, apresentamos, a seguir, os principais critérios atualmente existentes:

1. O Decreto-lei $n$ o $1.780 / 80$ exige que a empresa tenha faturamento igual ou inferior a 3 mil ORTN para se beneficiar de isençáo do imposto de renda e do IPI. Tratase de um programa que visa náo só beneficiar as menores empresas em termos de reduçáo do custu tributário, mas também isentando-se de exigência de escrituração fiscal.

2. A Caixa Econômica Federal lançou o Promicro (Programa de Assistência Creditícia às Microempresas), que ajudava o crédito às empresas comerciasis e artesanais com faturamento até Cr\$ 6,3 milhóes no ano de 1979 e indústrias que faturaram até $\mathrm{Cr} \$ 15,9$ milhoes. Como se nota, a microempresa, para a Caixa Econômica Federal, é maior que a microempresa referida no Decreto-lei no 1.780 , pois se aquela alcançava em $1979 \mathrm{Cr} \$ 15 \mathrm{mi}$ lhões de receita, esta alcançava quase $\mathrm{Cr}_{r} \$ 2$ milhóes (3 mil ORTN).

3. Parâmetros do Cebrae para micro e pequena indústrias, escolhidos para uso em trabalho que engloba este (Dutra, 1982), e que são apresentados a seguir.

\subsubsection{Critérios adotados em trabalho específico}

Tentar-se-á, a seguir, distinguir a micro da pequena indústria para efeito de testar hipóteses em trabalho mais abrangente (Dutra, 1982).

No que se refere à microindústria, parece mais lógico o critério do Cebrae para caracterizar este porte de empresa. Além de as finalidades do Cebrae estarem mais relacionadas com os objetivos do estudo citado do que as finalidades dos outros organismos, ele foi o único que adotou um critério mais flexível. Enumerou seis variáveis qualitativas, mas só exịgiu enquadramento em três. Indicou quatro variáveis quantitativas, exigindo $o$ atendimento de somente duas. Cebrae:

São estes os aspectos qualitativos considerados pelo
- náo pertençam a grupos econômico-financeiros;

- não possuam administraçáo especializada fora da empresa;

- tenham estreita relaçáo pessoal do proprietário com os empregados, clientes e fornecedores;

- mantenham permanente dificuldade em obter crédito, mesmo a curto prazo;

- tenham falta de poder de barganha nas negociaçóes de compra e venda;

- apresentem integraçáo bastante estreita na comunidade local a que pertencem seus proprietários.

Exige o Cebrae que se atendam a três dos aspectos citados, sendo obrigatória a condição do primeiro.

Além disso, deverá atender a três das seguintes condiçóes quantitativas:

- tenha até 10 pessoas ocupadas na empresa;

- vendas anuais até 2.800 MVR;

- renda familiar anual de até $220 \mathrm{MVR}$;

- investimento fixo de até 900 MV.R.

O MVR (Maior Valor de Referência) é fixado semestralmente pelo Banco Central, nos meses de maio e novembro. Para efeito do trabalho citado (Dutra, 1982), foi utilizado o MVR de novembro de 1980 , isto é, Cr\$ 2.996,10. Este procedimento se deu em virtude de os empresários fornecerem dados sempre referentes ao ano que se findou. Assim, a microempresa não deveria ultrapassar Cr\$ 14.980 .000 de vendas anuais, Cr $\$ 1.498 .050$ de renda anual dos sócios ou $\mathrm{Cr} \$ \mathbf{5 . 3 9 2 . 9 8 0}$ de investimento fixo.

No que se refere à pequena indústria, os critérios do Cebrae são:

- vendas anuais até 20 mil MVR;

- pessoal ocupado até 100.

Como se pode verificar, além dos aspectos qualitativos, geralmente subjetivos, a maior diferença entre a micro e a pequena empresa, segundo os critérios do Cebrae, é feita a nível de vendas e de pessoal ocupado.

\section{REVISÃO DA LITERATURA DE MARKETING DE MICRO/PEQUENA EMPRESA}

$\mathrm{Na}$ literatura, dificilmente se encontra uma obra exclusivamente dedicada a uma das áreas funcionais das empresas de menor porte. $O$ mais comum é encontrar aquelas que estudam a administraçăo das pequenas e médias empresas, destacando alguns aspectos de uma destas áreas, como por exemplo, marketing. Também aparecem na literatura artigos e publicafozes em revistas especializadas e periódicos com abordagens específicas sobre áreas específicas das pequenas empresas. Finalmente, existem as teses e dissertaçōes sobre as empresas de menor porte e os documentos de circulaçấo interna de organizaçóes que dão assistência às pequenas e médias empresas como o Cebrae, os Ceags, o Instituto de Administraçăo da FEA/USP e outros. 
Convém ressarlia, também, que a grande maioria das publicacóes sobre empresas de menor porte estuda as pequenas e médias empresas, sendo raras aquelas que só se preocupam com as pequenas e mais raras ainda as que estudam as microempresas.

Não obstante as inegáveis vantagens das grandes organizaçбes sobre as menores, tem sido reconhecido que, em alguns aspectos de importância como, por exemplo, para a área de marketing, as empresas de pequeno porte podem obter vantagens sobre as maiores. Isto pode ser verificado em estudos recentes como os de Guagliardi (1981a, 1981b).

Merrill (1959), ao lado dos inúmeros problemas que as firmas menores enfrentam, observa alguns pontos em que elas se apresentam em superioridade sobre as organizacóes maiores, que em regra sáo de natureza operacional. Entende que o desenvolvimento de novos produtos nas pequenas empresas é mais real ístico através das atividades diárias do que experiências em tubos de ensaio. Também é menos arriscado, pois pode ser feito em escala limitada e a custo mínimo. Considera também a pequena empresa mais flexível e versátil e, se estiver alerta com referência às reaçós do mercado e às açós dos concorrentes, tem mais agilidade de açăo, podendo decidir mais rapidamente quanto aos preços, prazos de entrega, alteraçóes na produçáo, atendimento de reclamaçóes etc.

Ainda segundo Merrill, ela procura também "despender grande esforço no controle da qualidade" para evitar cancelamentos de pedidos. Leva ainda vantagem em virtude da proximidade com o mercado, pois pode dar muito melhor assistência, ter maior contato pessoal com os clientes, além do custo dos fretes, geralmente menores.

A favor de um mercado próprio para as grandes empresas e outro para as pequenas, Gross (1959) observou que numerosos bens de consumo - que váo desde o automóvel até o cigarro, passando por eletrodomésticos e alguns produtos alimentícios - sta produtos típicos de grandes organizaçoses, pois requerem altos investimentos para desenvolver um esforço de propaganda por todo o país. Entende ainda que pelo mesmo motivo a grande empresa tem condiçóes de desenvolver uma marca própria e implantá-la no mercado nacional. Por outro lado, o princípio da diferenciaçáo, segundo Gross, pode ser mais atendido pelas pequenas empresas. Ela pode oferecer produtos diferentes para diferentes segmentos do mercado, podendo também atender mais rapidamente às novas necessidades do consumidor.

Ainda analisando as desvantagens da pequena empresa, a Organização Internacional do Trabalho (1963) observou que é característica de tais empresas ter dificuldades para efetuar pesquisas de mercado para conhecer as preferências e necessidades do consumidor. Além disto, "les es difícil hacer publicidad, presentar muestras, disponer de vitrinas e de salas de exposición, poner-se en relación con posibles compradores situados a cierta distancia, abrir-se paso en mercados nacionales e internacionales".

Frisou a publicaçá da OIT que a pequena empresa só tem sucesso tranqüilo quando se localiza próxima ao mercado, e este se caracteriza por dificuldade de transporte do produto, elevado custo deste transporte, ou que a demanda dos compradores é muito especializada ou individual. Ao contrário de certos autores que defendem que a pequena empresa deve cultivar $e$ aprimorar as vendas diretas para o consumidor final, a OIT entende que ela deve procurar vender a comerciantes, para beneficiar-se de vendas maiores, sem ter que desempenhar certas funcoes de vendas. Sugere que as cooperativas ou órgãos estatais que apóiam as pequenas empresas deveriam facilitar este tipo de comercializaçá. Poderiam também ajudar em práticas de marketing que uma empresa em separado náo tem condiçóes de fazer como: pesquisa do mercado, expansáo em mercados nacionais e estrangeiros, campanhas de propeganda e publicidade, participaçăo em feiras e exposiçoes, e ainda vender para órgáos públicos.

A eficiência da força de vendas, através de um adequado treinamento dos vendedores, foi considerada um dos instrumentos mais importantes da administraçăo de marketing (Roberts, 1964). Por isto, dá sugestóes sobre o que deve ser treinado no vendedor e como deve ser desenvolvido o treinamento, enfatizando que "a longo prazo esse é o caminho mais fácil - além de ser o caminho certo" para se atingir um melhor resultado financeiro.

Os princípios de estipulaçáo de preços que se aplicam particularmente a pequenas ou médias firmas foram discutidos por Oxenfeldt (1964). Evidenciou que em regra a dificuldade de as pequenas empresas competirem no préço deve-se ao fato de que elas têm custos mais elevados do que as grandes. Discute as políticas de preço a serem adotadas pelas pequenas empresas, se elas devem basear-se nos preços das grandes organizaçoes, se devem oferecer produtos de qualidade inferior. Lembra que $o$ problema de concorrencia de preços pelas grandes organizaçōes pode ser superado, explorando as vantagens naturais que a pequena empresa tem, pela maior proximidade com a clientela e flexibilidade das decisóes, como atendimento personalizado, valorizaçáo de cada cliente, relacionamento pessoal entre o cliente e o tomador de decisão, possibilitando favores especiais etc. Conclui observando que a escollha de preços deve levar em consideraçáo os clientes, os concorrentes e os custos. Lembrou que a segmentaçáo do mercado pode possibilitar à pequena empresa certos serviços específicos que permitem maiores preços, criticando a soluçăo simplista e sem imaginaçăo de reduçào de preços, que pode ser usada em casos especiais.

As técnicas de cálculo de custos para pequena empresa a fim de estabelecimento do preço foram estudadas por Fanello (s.d.). $O$ autor lembra a dificuldade que uma empresa com poucos controles tem de ratear os custos indiretos, principalmente quando a firma fabrica mais de dois produtos, e ainda quando atende pedidos por encomenda, como é comum entre as organizaços de menor porte. $O$ autor dá um tratamento especial ao cálculo e controle de custos, diferente das grandes organizaços, da forma que the pareceu mais adequada.

Em 1964, Brockway (publicaça brasileira em 1976) se preocupou com um "programa coordenado de marketing para a companhia de menor porte", sugerindo idéias quanto aos obje tivos, à organizaçáo de marketing, a planejamento e aos padróes de controles. To- 
davia, tais sugestóes stao mais aplicáveis às empresas consideradas de porte médio, por este estudo, e pouco aplicáveis às empresas pequenas e micro.

Um estudo de caso feito por Fox (1964) evidenciou que a empresa estudada, "como muitas firmas pequenas", carecia de registros e controles úteis às decisoes de marketing. Uma reestruturaçăo bem-sucedida deu ênfase aos controles de produtos e da força de vendas, com decisóes rápidas para atender às exigências do mercado, um plano de incentivo aos vendedores, tudo baseado num programa de vendas para um segmento específico do mercado.

Entre os tipos de serviços à pequena empresa industrial que um programa governamental deve encarar, para proporcionar 0 desenvolvimento, destaca-se 0 apoio gerencial de marketing (Stanley \& Morse, 1965). Eles observaram que "é básico um programa de treinamento e aconselhamento que dá uma especial aterção às funçőes de marketing". Entre as necessidades das pequenas empresas, os autores enfatizam primordialmente a pesquisa de mercado para conhecer as tendências da demanda, as possibilidades de novos produtos e a reativação de produtos já existentes. Os mesmos autores sugerem, entre outras, o treinamento em técnicas de pesquisa para os pequenos empresários. Pequenos industriais aumentaram o seu mercado, abrindo novos canais de distribuiçáo através do uso de atacadistas, pontos de varejo, agrupamento em associaçбes ou cooperativas - estas, principalmente para o mercado externo. Neste particular, lembra a experiência vivida pela India que, em 1963 criou a Export Assistance to Small Industry, entidade estatal que objetivou ajudar os pequenos industriais na exportação, orientando-os. Sugere ainda um segmento de mercado, até hoje não aproveitado pelo Brasil, que é o poder público, o governo como comprador. Os EUA e a India desenvolveram programas neste sentido, com notável sucesso.

Entre as pesquisas efetuadas no Brasil sobre pequenas e médias empresas, convém lembrar a de Vieira (Vieira, Camargo \& Manzoli, 1967), como coordenador do Programa Delft, que analisou todas as funçōes das PME de autopeças, senāo que no que se refere a marketing chegou a alguns resultados que merecem ser considerados. Conciuiu que as pequenas empresas têm entre si uma acirrada concorrência. Quando esta se dava nos preços, havia uma tendência d̀ baixa, alijando as mais débeis do mercado, ou porque perdiam a clientela e não suportavam o dumping imposto por outras, ou porque redu. ziam tanto os preços que se descapitalizavam. As "técnicas" utilizadas eram principalmente: concorrência nos preços ou com promoçóes de descontos, facilidades de vendas a crédito, melhor qualidade, entregas mais rápidas e com maior regularidade, tratamento melhor da clientela, localização da indústria etc.

Foi ainda sob a supervisáo de Vieira (Vieira, Camargo \& Manzoli, 1968), no Programa Delft, que se analisaram as PME do setor têxtil e se concluiu com relaçáo à qualidade que, "quanto menor a empresa, maior a possibilidade de ocorrência de defeitos nas mercadorias vendidas". Para ele, isto causa uma desvantagem a pequena empresa, em comparação com a média, pois resulta em queda nos lucros, por se ver obrigada a reduzir os preços.
Por outro lado, abre novas perspectivas para as pequenas, que procuram solucionar o problema com a criaçáo de seção de varejo para a venda de refugos, atingindo então outro segmento de mercado. Com o controle de qualidade, observou que as pequenas empresas dão maior relevância à seleção de matérias-primas, e depois do processo de fabricação. Acrescentou que a falta de controle de qualidade durante o processo de produção é elaborada, em regra, de modo empírico e deficiente, sendo um dos motivos das dificullades de sobrevivência das pequenas empresas de Sáo Paulo na luta pelo mercado com as empresas de porte médio e grande.

Outro estudo sobre o assunto é o de Richers, Figueiredo \& Hamburger (1970), os quais, em pesquisa realizada em 167 empresas de três capitais do país (Sáo Paulo, Porto Alegre e Salvador), relataram que, em resposta d pergunta sobre quais os problemas que as pequenas empresas têm em maior intensidade que as grandes, 29 entrevistados responderam que têm menos recursos financeiros e 16 disseram que têm desvantagens na organizaçăo e/ou distribuição; um número maior falou de vários outros problemas, entre os quais.alguns ligados à administraçá de marketing, a saber: preços, qualidade, concorrência, representantes, clientela, flutuaçóes do mercado etc. $\mathrm{O}$ fato de os problemas financeiros despontarem em primeiro lugar náo indica que aquelas empresas não têm problemas de marketing.

Tão-somente. injeção de recursos financeiros não parece ser o mais importante nas pequenas organizaçoses. 0 capital, sem adequar a técnica ao porte da empresa, se esvaziaria e novas necessidades de recursos financeiros surgiriam em maior intensidade. Parece-nos que procurar descobrir o que as microempresas, pelas suas características específicas, fazem ou podem fazer para se autofinanciarem, aproveitando os pontos positivos ou as vantagens que tiverem sobre as grandes, é a melhor contriburiçáo àquelas.

No tocante às exportaçōes de pequenas empresas, a Small Business Administration (1971) fez um levantamento das dificuldades e das oportunidades que a pequena empresa dos EUA tem e as sugestóes para superar aquelas e aproveitar estas. Destaca que a propaganda e a promoção sáo instrumentos-chave de marketing internacional, para que os produtos sejam conhecidos pelos consumidores do exterior. Os EUA dispoem de agências de programas especializadas no comércio exterior que podem suprir as deficiências naturais das pequenas empresas. Faz ainda consideraçoes sobre os variados instrumentos de marketing utilizáveis na exportaça, desde o conhecimento do mercado consumidor ao apreçamento, passando pelos canais de distribuiçăo e outros instrumentos.

Tais consideraçóes da SBA, somente agora, 10 anos após a publicaçáo da referida obra, podem ser aproveitadas pelas pequenas empresas brasileiras, para as quais o mercado externo é virtualmente desconhecido,

Uma visto superficial sobre marketing de PME foi dada por Roe (1975). Discute os vários instrumentos úteis à administração de marketing, principalmente: a força de vendas abordando mais os métodos de vendas: organização, controle, incentivos do corpo de vendedores; propaganda, com seus objetivos, conteúdo e veículos; a promoçato de vendas, relacionando algumas técni- 
cas; a pesquisa de mercado do produto e do consumidor; as políticas de apreçamento, a utilizaçăo de alguns canais de distribuição etc.

Não obstante todas as técnicas discutidas pelo autor serem, de fato, aplicáveis às PME, a obra não traz contribuiçóes pessoais para a administração de marketing das empresas menores, porque se limita a comentar as práticas já exaustivamente discutidas na literatura de marketing e náo comenta como, quando e por que tais práticas sấo utilizáveis nas PME.

Bem mais útil é o documento publicado pelo Centro do Comércio do Estado de São Paulo (1976) que, não obstante a sua simplicidade, é dirigido especialmente aos pequenos empresários do comércio, sugerindo técnicas específicas para as empresas de menor porte. $O$ trabalho dá ênfase especial à motivaçăo do consumidor, ao planejamento promocional, incluindo sugestoes para veículos de propaganda específicos e meios de promoçáo de vendas, também à força de vendas com ênfase para o treinamento dos vendedores etc.

Uma pesquisa feita na cidade de Santa Maria (RS), em 1.273 empresas, pelo Ceag-RS (1977), constatou que $71 \%$ das empresas têm como seu mercado principal "só o município", o que é consistente com outros estudos que concluíram que o mercado da pequena empresa tem área geográfica restrita. $O$ mesmo estudo concluiu que $21 \%$ dos principais problemas se encontravam no "mercado consumidor" e $42 \%$ dos entrevistados gostariam de receber treinamento gerencial em marketing.

Resultado semelhante se deu com o levantamento feito pelo Prodec (1977/78), que concluiu que quase 63\% das empresas têm como seu mercado principal a própria cidade.

O Ceag-SE (1979) analisou as pequenas empresas de beneficiamento do coco e concluiu serem muito incipientes as seguintes práticas de marketing: pesquisa de mercado, análise das vendas, promoçá, propaganda e cálculo de custos para o apreçamento. Relatou que a concorrência se faz principalmente através de reduçáo de preços. Por uma questáo de costume, ao contrário de pequenas empresas de outros gêneros, as empresas de beneficiamento de coco se orientam mais para os supermercados de outras cidades, industrias texteis e alimentares.

No plano regional, merece mençato a pesquisa de Cezário (1979) que, num trabalho sobre a pequena indústria de Londrina, concluiu que $40 \%$ vendem predominantemente para 0 munić́pio e região e nenhuma das demais "vende exclusivamente para outras regiós fora do norte paranaense". Algumas práticas que interessam a marketing foram objeto de atençáo do estudo e se encontram nas tabelas 4 e 5 .

Tabela 4

Cálculo do custo do produto

\begin{tabular}{lcr}
\hline Cálculo do custo & Indústria & $\%$ \\
\hline Exatamente & 14 & 70 \\
Aproximadamente & 4 & 20 \\
Não sabe & 2 & 10 \\
Total & 20 & 100 \\
\hline
\end{tabular}

Por experiência pessoal do pesquisador, sabe-se que o alto percentual para o item que calcula exatamente o custo do produto deve ser admitido com reservas, uma vez que é comum os pequenos empresários calcularem a mão-de-obra e a matéria-prima, mas não calcularem os custos indiretos, ou náo o fazerem corretamente.

Ainda este estudo evidenciou que as pequenas empresas industriais de Londrina năo utilizam, na sua maioria (85\%), o planejamento, pois não fazem previsáo de vendas. Resultado interessante para o produto é que nas empresas pesquisadas, em regra, existe uma preocupação grande com a qualidade do produto. Para $75 \%$ da amostra, quem efetua o controle de qualidade é o proprietário e em $20 \%$ dos casos, os chefés.

Com relaçáo ao instrumento de marketing propaganda, o estudo evidenciou, conforme a tabela 5 , que as pequenas empresas não utilizam, na sua maioria, este instrumento. Apenas 10\% divulgam através de jornais e outros $10 \%$ através das feiras e exposiçoes da Sudesil (Superintendência do Desenvolvimento Industrial de Londrina).

Tabela 5

Utilização da propaganda pelas pequenas empresas

\begin{tabular}{lcc}
\hline \multicolumn{1}{c}{ Meios } & Indústrias & $\%$ \\
\hline Jornal & 2 & 10 \\
Exposição da Sudesil & 2 & 10 \\
Agências de propaganda & - & - \\
Não fazem uso & 16 & 80 \\
Total & 20 & 100 \\
\hline
\end{tabular}

O estudo de Dutra (1982) teve também como objetivo confirmar ou não tais resultados, dando um passo adiante que é o de identificar se as pequenas indústrias da região náo utilizam $o$ instrumento porque não o entendem como sendo viável ou necessário, ou porque não sabem como fazer para utilizá-lo.

Ainda no plano regional, convém citar o levantamento de problemas elaborado pelo NDE/UEL (1979) em conjunto com o Programa Paranaense de Treinamento de Executivos (PPTE). Divididos os problemas em internos e externos, os resultados mostraram que $70 \%$ dos empresários alegaram dificuldades em vendas como principal problema interno e $80 \%$ alegaram concorrência como o problema externo que mais os preocupa. Como ambos estáo relacionados a marketing, acredita-se que essa seja área carente para os pequenos empresários da regiáo do Norte do Paraná.

O Ceag-SP (1979), executando o Promicro nas cidades de Sáo José do Rio Preto, Araçatuba e Birigui e se utilizando de uma amostra de 248 empresas, detectou as carências apresentadas na tabela 6 .

O Ceag-SP (1980), em seu relatório sobre as microempresas de São José do Rio Preto assistidas em 1979, registrou, entre as "principais necessidades apontadas pelas próprias empresas", dois itens da área de marketing classificados entre os quatro primeiros lugares. As principaris necessidades detectadas foram: mao-de-obra, com 15\% de incidência; programaçăo e controle da produçáo/ produtividade, com 14\%; mercado/baixo faturamento/ falta de infra-estrutura de vendas, com 13\%; controle de custos/formaçro do preço de venda com $13 \%$ das empre- 
Tabela 6

Principais necessidades apontadas por pequenas empresas em três cidades do interior de São Paulo

Necessidades

Incidência

(\%)

Mão-de-obra (especializada ou não)

Programação e controle de produção/produtividade

Mercado/baixo faturamento/falta de infraestrutura

de vendas

13

Controle dos custosf formação do preço de venda

13

Controles contabilidade, financeiro e fiscal

Planejamento da organização/gerência

Matéria-prima (obtenção)

Financiamento (falta de apoio)/capital de giro

Controles gerais/administração de estoques

Relacionamento do pessoal no trabalho

Instalações/equipamentos

Total

sas - seguindo-se então mais sete itens referentes a outras necessidades administrativas, de pessoal, finanças e de controle nas empresas.

Como se observa, os problemas ligados a marketing aparecem novamente, ocupando a terceira e a quarta posiçóes na preocupação dos empresários daquelas cidades.

Também o estudo elaborado por Bortoli Neto (1980) sobre PME detectou que entre os problemas das pequenas e médias empresas do setor industrial, 0 de maior intensidade se encontrava na área de vendas. Concluiu que "do total de 30 empresas desse setor, 22, ou $73,3 \%$, estão com desequilibrio nas vendas, quatro empresas com deficiência na área administrativa e apenas três empresas industriais apresentaram problemas na área de produção". Concluiu ainda o trabalho que, de todas as empresas analisadas, incluindo indústrias, comércio e serviços, a maior incidência de problemas ocorreu na área de vendas, "sendo mais significativa para as empresas do se tor industrial".

O trabalho de Bortoli Neto, que conclui que $81,5 \%$ dos problemas estratégicos das empresas industriais se situam na área de vendas, vem a corroborar os resultados de outros trabalhos similares sobre problemas de natureza estratégica.

Em estudo sobre os dirigentes das pequenas e mé. dias empresas, Teixeira (1981) constatou que, quanto ao sistema de informações gerenciais das PME, entre os dados mais ligados a marketing só havia a contento as informaçôes sobre vendas totais e quantidade produzida. No entanto, os dados de vendas por área, vèndedor, vendas por produtos, vendas por cliente, em regra náo se encontravam à disposição dos pequenos empresários. $\mathrm{O}$ sistema de informaçđes do marketing praticamente não existe na pequena empresa, como evidenciam tais resultados.

Outros estudos que focalizaram alguns aspectos de marketing das empresas de menor porte foram os de Guagliardi $(1981 a, 1981 b)$, que abordaram as atividades de exportação e a percepçáo dos executivos das empresas exportadoras. Entre outras conclusoes, destacam-se as seguintes, que se referem também às empresas de menor porte. Empresas de portes diferentes tiveram percepcoes diferentes quanto: à competitividade de seus produtos no mercado internacional, ao nível de absorçáo da produção pelo mercado interno, à possibilidade de o importador determinar os preços dos produtos etc. Além disso, empresas pequenas/micro, mais que as grandes, concordaram que exportar é mais lucrativo que vender no mercado interno. $O$ mesmo estudo mostrou que a força de venda ou o vendedor do mercado externo tem menor influência sobre sua supervisto nas micro/pequenas que nas médias e gràndes empresas. Além disso, é neste porte de organização (micro/pequenas) onde se enfrentam maiores índices de burocracia, quando comparados aos das empresas de porte superior.

No Brasil, dois órgãos governamentais, Cebrae e Cacex, deverão exercer uma ação conjunta para a formação de consórcios de pequenas e médias empresas, destinados à exportação. Isto será desenvolvido através do Programa Nacional de Apoio à Pequena e Média Empresas Exportadoras (Pronaex), "'principalmente na prestação de assistência técnica, para que, uma vez estruturadas, as pequenas empresas se engajem melhor e mais eficientemente no programa de exportaçāo do governo" (Planejamento Desenvolvido, jul/ago. 1981).

\section{CONCLUSÃO}

Como se pode observar, estudos específicos de marketing de pequenas empresas sáo raros e ratíssimos são os que abordam a aplicação de marketing nas microempresas. Tal carência de estudos dirigidos especialmente às funções de marketing nas micro e pequenas empresas representa desse modo um estímulo a pesquisas nesta área e ao desenvolvimento de programas de apoio gerencial que possibilite capacitar seus dirigentes a gerenciar melhor suas organizaçóes.

Como se pode notar também neste trabalho e em próximos relacionados com o assunto, as micros e pequena empresas deveráo receber atenção ainda maior do que têm recebido a nivel de programas específicos de financiamentos dos bancos oficiais e da eliminação de entraves burocráticos pelo ministro da Desburocratização, porque elas representam a curto prazo, um papel significativo na geração de empregos e de riqueza.

$E$, em função da sua atuação em todo o território brasileiro, a níveis locais e regionais, esforços em todos os estados devem ser feitos, no sentido de sensibilizar a população, o governo e os legisladores sobre a importância dessas empresas, a exemplo do que tem sido feito em Sáo Paulo, pela Associação Comercial.

\section{REFERENCIAS BIBLIOGRÁFICAS}

Barros, Frederico J.O. Robalinho de \& Modenesi, Ruy Lirio. Pequenas e médias indústrias. Rio de Janeiro: Ipea/Inpes, 1973.

Bortoli Neto, Adelino de. Tipologia de Problemas das pequenas e médias empresas. Dissertaçáo de mestrado. 
São Paulo, Faculdade de Economia e Administração da USP, 1980.

Brockway, George R. Programa coordenado de markting para companhia de menor porte. In: Administrando a pequena e média empresa. São Paulo, Management Center do Brasil, 1976.

Carmelo, Milton Huppert Monte \& Schoeps, Wolfang. Administração contábil $\varepsilon$ financeira na pequena empresa brasileira. Rio de Janeiro, Fundação Getulio Vargas, 1970.

Ceag-SE. Centro de Assistência Gerencial à Pequena e Média Empresa do Estado de Sergipe. Relatório de atividades. 1979.

Ceag-SP. Centro de Assistência Gerencial à Pequena e Média Empresa do Estado de São Paulo. Diagnóstico das empresas de beneficiamento do coco do estado de Sergipe. 1979.

Ceag-SP. Centro de Assistência Gerencial à Pequena e Média Empresa do Estado de São Paulo. Relatório de atividades de 1979. (Não publicado.) São Paulo, 1980.

Ceag-RS. Centro de Assistência Gerencial à Pequena e Média Empresa do Estado do Rio Grande do Sul, Relatório de atividades. 177.

Centro do Comércio do Estado de São Paulo. Técnicas de marketing para a pequena e média empresa Comercial. São Paulo, CCESP/Senac, 1976.

Cezário, Ana Cleide Chiarotti. Industrialização e pequenos empresários de Londrina. Dissertaçáo de mestrado em ciências sociais. São Paulo, USP, 1979.

Dutra, Ivan. Identificação de necessidades e utilização dos instrumentos de marketing na micro e pequena empresa industrial de Londrina-PR. Disertação de mestrado. São Paulo, USP, 1982.

Fanello, Antonio. A organização de uma pequena empresa. Lisboa, Pórtico, s.d.

Fibge. Fundação Instituto Brasileiro de Geografia e Estatística. Anuário brasiliero de geografia e estatistica. 1970.

Fox, Wiliard M. Operação recondicionamento: reestruturação da organização de marketing. Sáo Paulo, Management Center do Brasil, 1964.

Fracarolli, Luiz Machado. Pequena e média empresa: aspectos legais. São Paulo, Pioneira, 1975.

Gross, Horbert. Petite entreprise et grand marché. Paris, Les Editions d'Organization, 1959.

Guagliardi, J.A. A orientação de marketing de empresas exportadoras de manufaturados em São Paulo. Revista de Administração, 16(2): 69-107, abr./jun. 1981a. exportadoras de manufaturados vêem as atividades de exportação. Revista de Administração, 16(3):47-75, jul./set. $1981 b$.

Merrill, Harwood F. A pequena ou média empresa no atual mundo de negócios. In: Management for the smaller company. New York, American Management Association, 1959.

NDE/UEL. Núcleo de Desenvolvimento Empresarial Universidade Estadual de Londrina. Relatório do Promico. Londrina, 1979.

Organizaçấo Internacional do Trabalho. Al servicio de la pequena industria. Genebra, 1963.

Oxenfeldt, Alfred R. Princípios de estipulação de preços para pequenas e médias empresas. In: Administrando a pequena e média empresa. São Paulo, Management Center do Brasil, 1964.

Prodec. Programa de Desenvolvimento da Pequena e Média Empresa Comercial. Relatório final do projeto-piloto. $1977 / 78$.

Rattner, Henrique; Durand, J.C.G.; Rodrigues, L.M. \& Pessoa de Barros, S.M. Pequena e média empresa no Brasil: 1963/1976. São Paulo, Símbolo, 1979.

Richers, Reimar; Figueiredo, Orlando \& Hamburger, Polia. Administração de vendas na pequena empresa brasileira. Rio de Janeiro, Fundação Getulio Vargas, 1970.

Roberts, Paul. Treinamento de vendedores para aumentar as vendas e reduzir as respectivas despesas. In: $A d m i$ nistrando a pequena e média empresa. São Paulo, Management Center do Brasil, 1964.

Roe, C. Graeme. Marketing para a pequena e média empresa. Rio de Janeiro, Hachete do Brasil, 1975.

Small Business Administration. Export marketing for smaller firms. D.C., 1971.

Stanley, Eugene \& Morse. Modern small industry for developing Countries. New York, McGraw-Hill, 1965.

Teixeira, H.J. O trabalho dos dirigentes de pequenas e médias empresas. Revista de Administração, 16(3): 76-94, jun./ago. 1981.

Vieira, Dorival T.; Camargo, Lenita C. \& Manzoli, Flávio F. Pequenas e médias indústrias de autopeças. São Paulo, Programa Delft, IA/FEA/USP, 1967.

\& Pequenas e médias

indústrias têxteis. São Paulo, Programa Delft, IA/FEA/ USP, 1968.

Wipplinger, Gunter. Transferência de tecnologia para as PMEs. In: Anais do I Congresso Brasileiro da PME. Digesto económico. Edição especial, 1980. 